\title{
Vital Statistics of Panstrongylus geniculatus (Latreille 1811) (Hemiptera: Reduviidae) under Experimental Conditions
}

\author{
Daniel R Cabello/ ${ }^{+}$, Itamar Galíndez
}

\author{
Departamento de Biología, Facultad de Ciencias, Universidad de Los Andes, Mérida, 5101 Venezuela \\ *Núcleo Universitario Rafael Rangel, Trujillo, Venezuela
}

A statistical evaluation of the population dynamics of Panstrongylus geniculatus is based on a cohort experiment conducted under controlled laboratory conditions. Animals were fed on hen every 15 days. Egg incubation took 21 days; mean duration of 1st, $2 \mathrm{nd}, 3 \mathrm{rd}$, 4th, and 5 th instar nymphs was 25 , 30, 58, 62, and 67 days, respectively; mean nymphal development time was 39 weeks and adult longevity was 72 weeks. Females reproduced during 30 weeks, producing an average of 61.6 eggs for female on its lifetime; the average number of eggs/female/week was 2.1. Total number of eggs produced by the cohort was 1379. Average hatch for the cohort was 88.9\%; it was not affected by age of the mother. Age specific survival and reproduction tables were constructed. The following population parameters were evaluated, generation time was 36.1 weeks; net reproduction rate was 89.4; intrinsic rate of natural increase was 0.125; instantaneous birth and death rates were 0.163 and 0.039 respectively; finite rate of increase was 1.13; total reproductive value was 1196 and stable age distribution was $31.2 \%$ eggs, $64.7 \%$ nymphs and $4.1 \%$ adults. Finally the population characteristics of P. geniculatus lead to the conclusion that this species is a $K$ strategist.

Key words: vital statistics - Triatominae - Venezuela - Panstrongylus geniculatus

Panstrongylus geniculatus (Latreille 1811), is widely distributed in America; it is found from southern Mexico to northern Argentina. It has epidemiological importance since it has been found naturally infected with Trypanosoma cruzi from the beginning of this century (Chagas 1912).

In Venezuela, it has been captured in many states (Ramírez Pérez 1987). Pifano (1986) studying the urban Chagas' disease in the valley of Caracas reported individuals of $P$. geniculatus in human dwellings, apparently associated to the marsupial Didelphis marsupialis.

It is attracted by light and has been collected in human dwellings, but it does not colonize them (Miles et al. 1981); it is a sylvatic species (Lent \& Wygodzinsky 1979, Zeledón 1983).

It has been little studied because of the difficulties for rearing and maintenance, and for the low number of collected specimens (Miles et al. 1981, Ramírez Pérez 1987); therefore, very little literature has been published on its biology, ecology and epidemiology. Barreto (1967) studied some ecological aspects and indicated a close association with some mammals like armadillo. Lent and Jurberg (1969) registered a life cycle of 531

\footnotetext{
${ }^{+}$Corresponding author. Fax: +58-74-401286

Received 22 April 1997

Accepted 15 January 1998
}

days in animals reared in laboratory coming from eggs captured in Trinidad. Galíndez (1990) studied the life cycle under laboratory conditions and registered a duration of 269 and 297 days in nymphs fed on hen and D. marsupialis, respectively.

Here we present the results of a study of $P$. geniculatus fed only on hen, under controlled constant environmental conditions, with special emphasis on its demographic characteristics, in order to contribute to the kwowledge of the population dynamics of this species.

\section{MATERIALS AND METHODS}

The population of $P$. geniculatus used in this experiment was obtained from a colony founded by a single female collected in a human dwelling in the area of San Jacinto, located in the city of Trujillo, Trujillo State, Venezuela. The colony was kept in a climatic chamber at $26 \pm 3^{\circ} \mathrm{C}$ and $90 \pm 10 \%$ $\mathrm{RH}$, and fed on hens.

Vital statistics described in this study were based on a cohort constituted by 63 recently laid eggs ( 0 to $48 \mathrm{hr}$ old); these were kept in $150 \mathrm{~cm}^{3}$ glass containers until all viable eggs hatched; then, all 1st instar nymphs were transferred to a 3,785 1 broad mouth jar, covered with nylon mesh and provided with vertically placed strips of paper in order to allow insects to climb to the jar top at feeding time and provide them resting places and serve as laying sites. 
Cohort was kept under the same conditions of temperature and relative humidity as the colony and fed every 15 days, during $30 \mathrm{~min}$, using hens placed on a wooden box with holes at the botton, through which the cohort top jar could be inserted (Gómez Núñez \& Fernández 1963). Bugs climbed to the top and fed through nylon mesh. The cohort was censused daily during the nymphal instars and weekly in the adults. Daily, we checked the number, instar, and sex (if adults) of live and dead individuals; weekly, we counted the eggs laid by each female which were maintained during five weeks; after this time, we counted the number of 1 st instar nymphs alive in order to know the age specific fertility. Animals were followed until the death of the last adult individual.

The weekly death schedule provided the necessary information to construct a complete horizontal life table (Deevey 1947). To carry out the calculations, the method of Dublin et al. (1949) was followed. For the definitions of the components of life tables and its formulae, the criterion of Rabinovich (1972a) was followed.

This mortality schedule, coupled with female age specific fecundity, was used to calculate the intrinsic rate of natural increase, the net reproductive rate, the instantaneous birth and death rate (Birch 1948), and the age specific reproductive value (Fisher 1930). Besides, the stable age distribution was calculated. For the statistics comparisons we used t of student, $\mathrm{x}^{2}$ tests and analysis of variance.

\section{RESULTS}

Life cycle - In Table I, a statistical summary of life cycle characteristics is shown. Average time from ovoposition to hatching was about three weeks. After entering to the adult stage, males lived an average of 1.1 times longer than females. A frequency table of time spent in each instar provided an estimate of the duration of each nymphal instar since the cohort was not followed individually. The table was based on number of individuals entering a particular instar and the time they spent on it, number dying in that instar and number molting to the following one. Relative duration of nymphal instars was longer as the insects developed into more advanced stages.

Mean longevity as adults was 39.8 weeks for males and 33.7 weeks for for females. Maximum longevity was 73 weeks for males and 65 weeks for females. Both were statistically significant greater for males than for females $(0.01<p<0.05)$.

Mortality - This information is given (a) as an age-specific schedule of mortality and (b) by developmental stage.

\section{TABLE I}

Statistical summary of life cycle characteristics of Panstrongylus geniculatus

\begin{tabular}{lrrrrrr}
\hline & $\mathrm{n}$ & $\overline{\mathrm{x}}$ & $\mathrm{SD}$ & $\mathrm{q}_{1}$ & $\mathrm{q}_{2}$ & $\mathrm{q}_{3}$ \\
\hline $\begin{array}{l}\text { Days of egg } \\
\text { incubation }\end{array}$ & 56 & 21.3 & 2.7 & 20 & 22 & 24 \\
$\begin{array}{l}\text { Days as nymph } \\
\text { 1st instar }\end{array}$ & 51 & 25.3 & 5.4 & 20.5 & 28 & 30 \\
2nd instar & 49 & 30.4 & 15.4 & 21.5 & 29 & 43 \\
3rd instar & 49 & 58.1 & 32.5 & 50 & 56.5 & 73 \\
4th instar & 49 & 61.7 & 32.7 & 43 & 68 & 78 \\
5th instar & 48 & 67.3 & 29.5 & 60 & 67 & 86 \\
$\begin{array}{l}\text { Days from egg } \\
\text { to adult }\end{array}$ & 48 & 274.8 & 25.7 & 234 & 269 & 283 \\
\hline
\end{tabular}

$\mathrm{n}$ : number of individuals; $\overline{\mathrm{x}}$ : mean; SD: standard deviation; $\mathrm{q}_{1}, \mathrm{q}_{2}, \mathrm{q}_{3}$ : first, second and third quantiles.

In Fig. 1 mortality is expressed as the probability of being alive at age $\mathrm{x}(\mathrm{lx})$. The greatest decrease in survival occurred at the beginning of the life cycle (egg stage and 1st instar nymph); in the other four instar nymphs almost all individuals survived. Thereafter (in adult stage), survival values showed a fairly linear age specific schedule of mortality without a period of greater risks.

In Table II, mortality is shown in terms of developmental stages. At the egg stage it was about $11 \%$; then, it registered a mortality lower than $9 \%$ in the 1 st instar nymph; it was 0 in the 3 rd and 4 th stages, and between 2 and $4 \%$ in the 2 nd and 5 th stages; not more than $15 \%$ of all nymphs died before reaching adult stage.

When bugs entered the adult stage, males predominated, on the average, by a ratio of 1.35 to 1.00. This suggests that females had slightly higher mortality risks during development than males, if a 1:1 sex ratio of eggs is assumed.

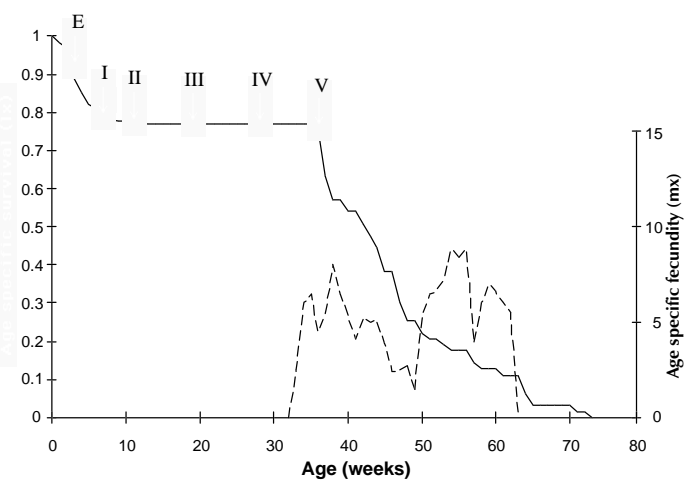

Fig. 1: survivorship and fecundity curves of Panstrongylus geniculatus. E: end of egg stage. I-V: end of 1st-5th nymphal instars, respectively. 
TABLE II

Percent mortality of Panstrongylus geniculatus by developmental stages

\begin{tabular}{lcc}
\hline Instar & $\begin{array}{c}\text { Relative } \\
\text { mortality }^{a}\end{array}$ & $\begin{array}{c}\text { Absolute } \\
\text { mortality }^{b}\end{array}$ \\
\hline 1st & 62.5 & 8.93 \\
2nd & 25.0 & 3.92 \\
3rd & 0 & 0 \\
4th & 0 & 0 \\
5th & 12.5 & 2.04 \\
Total nymph mortality & & $14.3^{c}$ \\
in cohort & & 11.1 \\
Embryonic egg mortality & & \\
\hline
\end{tabular}

$a$ : no. dead nymphs in a given stage divided by no. dead nymphs of all instars X 100; $b$ : no. dead nymphs in a given stage divided by no. nymphs that entered that stage $\mathrm{X} 100$; $c$ : not including eggs, e.g., with respect to the starting no. of 1 st instar nymphs.

Linear correlation analysis did not show any relationship between nymphal mortality and developmental time. Apparently, a longer developmental time is not necessarily accompanied by a higher mortality.

Life expectancy - It reached a maximum of 38.95 at the age of 8 weeks, i.e., during the 2 nd instar. Two increases in life expectancy were registered after egg hatching and before the end of the 2nd nymphal instar. Then, it was observed a constant decline with a regular slope during the remaining nymphal instars and the first weeks of the adult stage; thereafter it dropped lineally with small rises until arriving zero at 74 weeks of age (Fig. 2). Initial increase is interpreted as the result of having overcome the largest risks of first stages of the life cycle, as egg hatching and first molting. After overcoming these risks, 2nd instar nymphs attained the highest life expectancy.

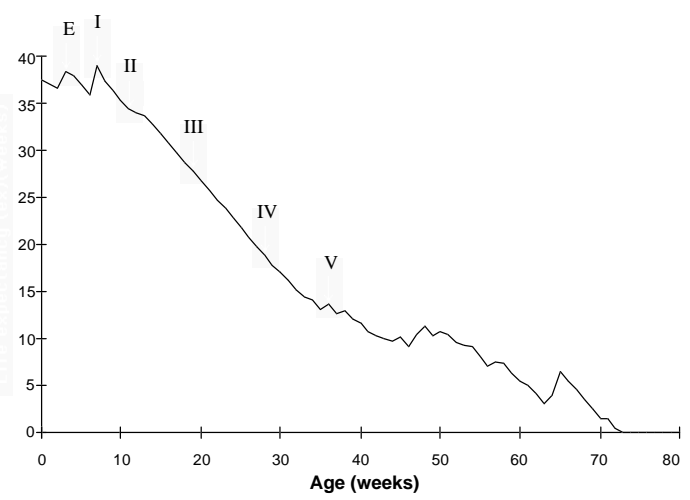

Fig. 2: life expectancy of Panstrongylus geniculatus since the egg was laid. Symbols as in Fig. 1.
Reproduction - In Fig. 1, besides survival, average age specific fecundity, expressed as number of eggs/female/week $(\mathrm{mx})$ is presented. It was registered a bimodal pattern, although irregular, curve; the reproductive peaks were at 40 and 55-58 weeks of age. Females stopped laying several weeks before death of last adult.

The average hatch (fertility) for the cohort was $88.9 \%$. Survival during embryonic development was not affected by the age of the female parent.

Age of first reproduction was at 34 weeks, with only about a two-weeks interval between entering the adult stage and first laying. Maximum reproduction occurred at 55-57 weeks. The total number of eggs produced by the cohort was 1379 in 30 weeks of reproductive life, the mean number of egg per female for its lifetime was 61.6 (SD:10.7), the average number of eggs/female/week was 2.1 (SD:1.3), and the number of eggs/female/week at the age of maximum reproduction was 8.8 (SD:4.7).

Life tables and population statistics - The age specific mortality schedule provided the necessary data for construction of life tables. The statistics of population characteristics are summarized in Table III.

Reproductive value - In Fig. 3 the average age specific reproductive value $(\mathrm{Vx})$ is observed. Adults attained the greatest contribution (69.4\%),

TABLE III

Population statistics of Panstrongylus geniculatus

\begin{tabular}{lc}
\hline Generational time (T) (weeks) & 36.1 \\
Net reproduction rate (Ro) & 89.4 \\
Intrinsic rate of increase (r) & 0.125 \\
Instantaneous birth rate (b) & 0.163 \\
Instantaneous death rate (d) & 0.039 \\
Finite rate of increase ( 1 ) & 1.13 \\
Finite birth rate (b) & 0.17 \\
Total reproductive value (V) & 1196.1
\end{tabular}

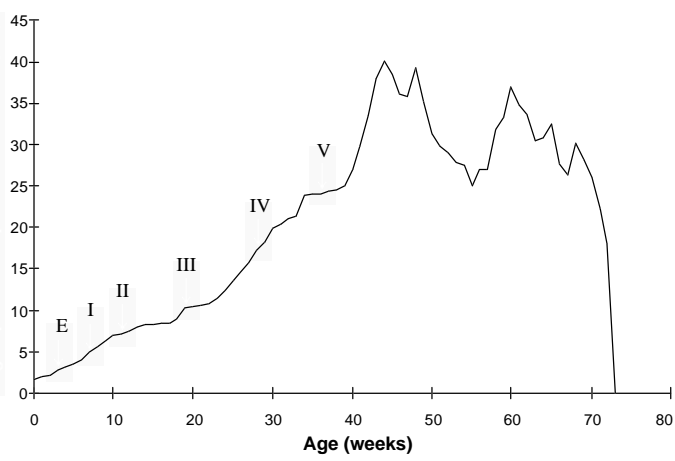

Fig. 3: age specific reproductive value of Panstrongylus geniculatus. Symbols as in Fig. 1. 
while egg and nymphal instars provided $0.34,0.95$, $1.7,4.6,7.8$, and $15.2 \%$, respectively. The greater values of Vx were registered few weeks (45-50) after molting to adult and at about 60 weeks of age. Thereafter, these values declined with a very abrupt slope until the end of the generation.

Colonizing ability - It is considered in relation to its dispersion and some other population parameters: (1) population growth rate - An intrinsic rate of natural increase of $0.125 /$ head/week is very low for an insect, even shorter than the indicated for most species of triatomines; (2) average longevity - The mean longevity values of the adults ranked between 33.7 and 39.8 weeks, which can be considered as extremely high for an insect species; (3) resistance to starvation for relatively short periods - In an additional experiment, 50 adult specimens ( 25 females and 25 males) were kept after only one food supply, and it was observed that they died between 50 and 70 days after their feeding, relatively low figures with relation to the indicated for T. infestans: up to 210 days in adults (Borda 1972); (4) dispersal capacity is apparently low Although there is not quantitative information about the dispersal capacity of $P$. geniculatus, it is valid to consider it lower than the one found in $R$. prolixus: no more than $15 \mathrm{~m}$ without vertebrate assistance (Rabinovich 1972a), since this species is more widespread than $P$. geniculatus; although the species could be increasing its dispersal potential since it has recently been found to colonize artificial structures in association to man and domestic animals (Valente et al. 1994); (5) survival curve is located between types I and II (Deevey 1947).

These five population characteristics indicate that $P$. geniculatus should be considered as an intermediate species $r$ - K, sensu Wilson and Bossert (1971) with a clear trend toward the extreme K, since it possesses adaptations of $r$ strategists, as resistance to starvation for short periods, and of $\mathrm{K}$ strategists, i.e., low growth rate, high average longevity, low dispersal capacity and the survival curve intermediate between I and II types.

\section{DISCUSSION}

In evaluating the results, we have taken into account the aspects of cohort study indicated by Rabinovich (1972a).

Life cycle - Duration of egg stage. The average incubation period, $21.3 \pm 2.7$ days was shorter than the 25.1 days egg developmental time for $P$. geniculatus obtained by Galíndez (1990), but is a little higher than the indicated for some other species of triatomines: 19.8 days in Triatoma infestans (Rabinovich 1972a); 19.1 days in T. maculata (Feliciangeli \& Rabinovich 1985); 19.9 days in
Rhodnius neivai (Cabello et al. 1987); 18 days in $R$. prolixus, 21.1 days in $R$. pictipes (Lent \& Valderrama 1977).

The total duration of the nymphal stages was 253 days, much shorter than 531 days given by Lent and Jurberg (1969) and close to that of Galíndez (1990), between 269 and 297 days, both considering time from egg to adult. Relative duration of 1st and 2nd nymphal instars were very close to the obtained by Lent and Jurberg (1969) and Galíndez (1990); however, there are some conspicuous differences in the other instars; Lent and Jurberg (1969) observed a short 3rd and an extremely long 4th nymphal instars, while Galíndez (1990) reported a long 3rd and a very short 4th nymphal instars. We did not register significant differences in developmental time between $3 \mathrm{rd}$ and 4th nymphal instars.

Total adult longevity was almost identical to that observed by Galíndez (1990). Maximum and mean longevity were greater for males than for females in agreement with the registered for most species of triatomines (Rabinovich 1972a, Feliciangeli \& Rabinovich 1985, Cabello et al. 1987).

Mortality - There was greater relative mortality in the 1st instar nymphs (62.5\%) than in any other developmental stage; mortality decreased as development progressed, with no mortality in 3rd and 4th instars and a slight increase in the 5th instar nymphs; however, this increase in mortality of the 5th instar nymphs was much lower than that observed in genus Triatoma and Rhodnius. On the other hand, Galíndez (1990) reported higher mortality values (26-30\%) in 3rd instar nymphs, contrasting with our results. This can be attributed to differences in feeding schedules and temperature conditions.

In terms of absolute mortality all our results showed figures smaller than the indicated for other species of triatomines (Rabinovich 1972a, Feliciangeli \& Rabinovich 1985, Cabello et al. 1987).

Reproduction - Although Lent and Jurberg (1969) did not have reproduction in their animals, our results showed that egg hatching percentage was consistent with the results registered for other species of triatomines (Perlowagora-Szumlewicz 1969, Rabinovich 1972a). The statistics of reproduction characteristics and its comparisons with other species are summarized in Table IV.

The interval between entering the adult stage and first laying was two weeks, these results are in line with the indicated for others species of triatomines: between 9 days and 4 weeks after its entering to the adult stage (Rabinovich 1972a,b, Feliciangeli \& Rabinovich 1985, Cabello et al. 1987). 
TABLE IV

Reproductive characteristics of some species of triatomines

\begin{tabular}{lcccc}
\hline & $\begin{array}{c}\text { Panstrongylus } \\
\text { geniculatus }\end{array}$ & $\begin{array}{c}\text { Triatoma } \\
\text { infestans }\end{array}$ & $\begin{array}{c}\text { Triatoma } \\
\text { maculata }\end{array}$ & $\begin{array}{c}\text { Rhodnius } \\
\text { neivai }\end{array}$ \\
\hline Age of first reproduction (weeks) & 34 & 23 & 18 & $15-17$ \\
Age of maximum reproduction (weeks) & $55-57$ & 34 & 36 & $31-40$ \\
Mean number eggs/week/female at age of & & & & \\
maximum reproduction & 9 & 38 & 34 & 28 \\
Number of weeks of reproductive life & 30 & 17 & 5 & $32-34$ \\
Mean number of egg for female on its lifetime & 62 & 150 & 502 & $724-1047$ \\
\hline
\end{tabular}

The general reproductive output of $P$. geniculatus was smaller than the reported for other species of triatomines; in general, the species began reproduction and reached its maximum reproductive effort at an older age. Although its number of weeks of reproductive life was longer, it laid less eggs per cohort, per female, and per female per week. It laid less eggs at the age of maximum reproduction, and ended its reproduction at an older age.

Life tables and population statistics - Generation time (T) was 36.1 weeks. This value is a little greater than the indicated for T. infestans, $R$. prolixus and $R$. neivai, but smaller than the indicated for T. maculata; the generation time is representative of the actual mean length of a generation in terms of population dynamics, and, therefore, it is useful for analyzing control approaches. Intrinsic rate of natural increase (r) was 0.125 ; it is much smaller than the indicated for R. neivai, and a little smaller than the reported for $R$. prolixus and $T$. maculata, but a little greater than the indicated for T. infestans. Finite rate of increase (1) was 1.13. It is very similar to the observed in T. maculata and $T$. infestans; these two increase rates provide estimates of the growth potential of $P$. geniculatus populations. These growth rates may be similar to those in the field because there were density effects operating in the cohort jar. Net reproductive rate (Ro) was 89.4, it is 4 times smaller than in $R$. neivai, 2 to 3 greater than in T. infestans and $R$. prolixus, but similar to the observed in T. maculata. The stable age distribution (SAD) was $31.2 \%$ eggs, $64.7 \%$ nymphs and $4.1 \%$ adults.

Considering that $P$. geniculatus is a $\mathrm{K}$ strategists, and also has low natural increase and net reproductive rates, long generation time, and small general reproductive output, we conclude that it is less likely than other species to become a significant household pest.

\section{ACKNOWLEDGMENTS}

To the anonymous reviewers whose suggestions improved the original manuscript.

\section{REFERENCES}

Barreto MP 1967. Estudos sôbre reservatorios e vetores silvestres do Trypanosoma cruzi xxi: Observações sobre a ecología do Panstrongylus geniculatus (Latreille, 1811) (Hemiptera: Reduviidae). Rev Brasil Biol 27: 337-348.

Birch LC 1948. The intrinsic rate of natural increase of an insect population. J Anim Ecol 17: 15-26.

Borda MR 1972. Algunos nuevos aspectos sobre biología y ecología de Triatoma infestans Klug, 1834, y su enemigo natural Telenomus fariai Lima, 1927. Breves notas referentes a Trypanosoma cruzi Chagas, 1909. Primer Congreso Latinoamericano de Entomología, Cuzco, Perú, p. 35.

Cabello DR, Lizano E, Valderrama A 1987. Estadísticas vitales de Rhodnius neivai Lent, 1953 (Hemiptera: Reduviidae) en condiciones experimentales. Mem Inst Oswaldo Cruz 82: 511-524.

Chagas C 1912. Sobre um trypanosomo do tatú, Tatusia novemcincta transmitido pela Triatoma geniculata Latreille, 1811. Posibilidade de ser o tatú um depositario do Trypanosoma cruzi no mundo exterior. (Nota previa). Brasil Medico 26: 305-306.

Deevey ES 1947. Life tables for natural populations of animals. Quart Rev Biol 22: 283-314.

Dublin LI, Lotka AJ, Spiegelman M 1949. Length of Life (Rev. Edit.), Ronald Press, New York, NY, 157 pp.

Feliciangeli MD, Rabinovich JE 1985. Vital statistics of Triatominae (Hemiptera: Reduviidae) under laboratory conditions. II. Triatoma maculata. J Med Ent 22: 43-48.

Fisher RA 1930. The Genetical Theory of Natural Selection, Claredon Press, Oxford, $268 \mathrm{pp}$.

Galíndez I 1990. Colonización y Ciclo de Vida de Panstrongylus geniculatus (Latreille, 1811)(Hemiptera: Reduviidae: Triatominae), Universidad de Los Andes, Núcleo Rafael Rangel, Trujillo, Mimeografiado, $34 \mathrm{pp}$.

Gómez Nuñez JC, Fernández J 1963. La colonia de Rhodnius prolixus en el Instituto Venezolano de Investigaciones Científicas. Bol Dir Malariol y San Amb 3: 132-137.

Lent H, Jurberg J 1969. Observações sobre o ciclo evolutivo em laboratório do Panstrongylus geniculatus (Latreille, 1811) (Hemiptera: Reduviidae: Triatominae). An Acad Brasil Cienc 41: 125-131. 
Lent H, Valderrama A 1977. Observações, em laboratório, sobre o ciclo evolutivo de Rhodnius prolixus STAL, 1859, $R$. pictipes STAL, 1872 e $R$. neivai LENT, 1953. Rev Brasil Biol 37: 325-344.

Lent H, Wygodzinsky P 1979. Revision of the triatominae (Hemiptera: Reduviidae), and their significance as vectors of Chagas' disease. Bull Am Mus Nat Hist 163: 123-520.

Miles MA, De Souza AA, Povoa M 1981. Chagas' disease in the Amazon basin. III. Ecotopos of ten triatomine bug species (Hemiptera: Reduviidae) from the vecinity of Belém, Pará State, Brazil. J Med Ent 18: 266-278.

Perlowagora-Szumlewicz A 1969. Estudos sobre a biologia do Triatoma infestans, o principal vetor da doença de Chagas no Brasil. (Importância de algumas de suas características biológicas no planejamento de esquemas de combate a esse vetor). Rev Bras Malariol Doenças Trop 21: 117-159.

Pifano F 1986. El potencial enzoótico silvestre del complejo ecológico Schizotrypanum cruzi - Didelphis marsupialis - Panstrongylus geniculatus y sus incursiones a la vivienda humana del valle de Caracas
- Venezuela. Bol Acad Cienc Fis Mat y Nat 46: $143-$ 144.

Rabinovich JE 1972a. Vital statistics of Triatominae (Hemiptera: Reduviidae) under laboratory conditions. I. Triatoma infestans Klug. J Med Ent 9: 351-370.

Rabinovich JE 1972b. Vital statistics of Triatominae (Hemiptera: Reduviidae) under laboratory conditions. II. Rhodnius prolixus STAL. Abst 14th Intern Congr Entomol, Camberra, p. 81.

Ramírez Pérez J 1987. Revisión de los triatominos (Hemiptera: Reduviidae) en Venezuela. Bol Dir Malariol San Amb 27: 118-146.

Valente SAS, Valente VC, Neves AYP, Lima JAN, Araújo JEA, Noireau F 1994. Aspectos ecoepidemiológicos sobre a possível domiciliação do Panstrongylus geniculatus em Muaná, Pará. Rev Soc Bras Med Trop 27 (Supl. I): 113.

Wilson EO, Bossert WH 1971. A Primer of Population Biology, Sinauer Associates, Inc. Publishers, Stanford, $192 \mathrm{pp}$.

Zeledón R 1983. Vectores de la enfermedad de Chagas y sus características ecofisiológicas. Interciencia 8 . 384-395. 